\section{SP0036 FREE FATTY ACIDS: GOOD OR BAD IN RHEUMATOLOGY?}

L.A. Joosten ${ }^{1}$, Leo AB Joosten ${ }^{2,3}{ }^{1}$ Internal Medicine, Radboud University Medical Center, Nijmegen, Netherlands; ${ }^{2}$ Department of Internal Medicine, Radboud Universtiy Medical Center, Nijmegen, The Netherlands; ${ }^{3}$ Department of Medical Genetics, Iuliu Hațieganu University of Medicine and Pharmacy, Cluj-Napoca, Romania

Free fatty acids (FFA's) are grouped based on the length of their carbon chains into short chain fatty acids (SCFAs), medium chain fatty acids (MCFAs) and long chain fatty acids (LCFAs). The most FFAs are released after breakdown of triglycerides in adipose tissue and the liver. However, SCFAs including acetate, propionate and butyrate are derived from the fermentation of fibres in the gut. In this presentation, the good or the bad properties of FFA's to control or aggravate inflammation in general will be discussed. With special focus on rheumatic disorders, such as rheumatoid arthritis and gout. In addition, the synergy of LCFAs with damage associated molecular patterns (DAMPs) will be addressed. Finally, the therapeutic value of SCFAs will be discussed in rheumatic disorders.

Disclosure of Interest: None declared

DOI: 10.1136/annrheumdis-2018-eular.7849

THURSDAY, 14 JUNE 2018

\section{Inclusive school environment for young people with RMDs}

\section{SP0037 INCLUSION OF ILL CHILDREN INTO THEIR HOME SCHOOL BY REAL TIME EDUCATION}

\section{E. Janssens. Bednet vzw, Bednet, Leuven, Belgium}

The right to education, even when ill

It seems self-evident. Even when you are ill for a long time, you preserve the right to learn and keep your place in het social environment of your class group.

For 25 years now the right to education has been established as a right of every child, as formulated in the Convention on the Rights of the Child. Since 2006 Bednet makes sure that this fundamental right is fulfilled. Bednet takes care that children and youngsters who are absent for a shorter or longer period because of physical or mental illness, surgery or pregnancy, can continue attending the lessons - from their home and with their own class group. In the educational law it is called: synchronous internet education (SIE).

But it is only since 1 September 2015 that synchronous internet education (SIE) is structurally embedded in the educational system of the Flemish Community. This results in the right to SIE for every child with a chronic or long term illness.

Along with lessons, and all the rest

Bednet takes care that children and youngsters who are absent for a shorter or longer period because of physical or mental illness, surgery or pregnancy, can continue attending the lessons - from their home and with their own class group.

It is available for pre-school children from the age of 5, pupils of primary and secondary schools. The equipment and the counselling is free for schools and families, and this throughout the period in which the child needs it.

Bednet aims at limiting arrears in learning by providing a set of tailor-made lessons. This way 9 children out of 10 succeed in passing on to the next class despite their absence from school. Moreover Bednet makes an opening in the isolation of the child by enabling regular contacts with peers. The illness recedes to the background and the child is temporarily back with friends 'in his or her class group'. The non-profit organisation always collaborates with the parents, the school and other partners, such as the hospital schools and volunteers.

Bednet in practice: Bednet creates a live connexion between the pupil with an illness and his or her class group. The pupils and the teacher see the youngster on the flat screen at the back of the classroom. The child at home can direct a camera, enabling him or her to attend the lesson and/or talk to peers. Bednet uses a system that is easy to use. The pupil participates actively in the lesson, answers questions, can send and receive documents and take part in group work. Just as if the pupil were really sitting in the classroom.

Bednet operates with regional consultants in the different provinces. They do the follow-up of the children and confer with parents, hospital and school. They plan everything and take care of the concrete organisation. A technical helpdesk supports children and school throughout the project.

Bednet in numbers:

- In the first full school year during which Bednet was active (2007-2008), 37 children were supported.

- Since the start more than 1,900 children with a long time or chronic illness have used Bednet in 1,250 Flemish schools with synchronous internet education.
- The children and youngsters live in all parts of Flanders and Brussels. Two out of three Bednet users attend secondary school.

- Cancer remains the most common pathology with $21 \%$ of all users. Also patients with rheumatology belong to the target group of Bednet.

The future: Under the authority of the Flemish Government Bednet faces the big challenge of guaranteeing the right to SIE for each and every child with a long term illness. It is gradually being extended to cover all children with a long-term absence from school in the whole of Flanders. It is estimated that numbers could grow to 1.000 children in 2018.

Disclosure of Interest: None declared

DOI: 10.1136/annrheumdis-2018-eular.7669

\section{SP0038 RAIISING AWARENESS OF INVISIBLE ILLNESSES IN SCHOOLS AND EDUCATION}

\section{S. Ainsworth. RAISE, Liverpool, UK}

Introduction

RAilSE is a user-led research project inspired by the negative experiences that young people face while studying and living with an invisible illness. Many young people who live with chronic illnesses look no different to their healthy peers. The invisible nature of some illnesses can often lead to an invisible struggle, leading to misunderstandings, particularly in the case of young people. It can be a huge burden on the chronically ill to make the invisible, visible to others.

Objective: The main objective of RAilSE is to improve the standard of care given to young people with invisible illnesses in school and college and to create a resource to teach education professionals a series of strategies and techniques to support their students. RAilSE will also offer support to young people with invisible illnesses and aim to empower them to take control of their own health

Methods: A young patient of Alder Hey NHS Children's Foundation Trust decided to raise awareness of living with an invisible illness. A network of young people, parents, education and health professionals was created and a series of workshop and focus groups allowed each stakeholder to share their experiences and expertise as they inspired and advised the production of the RAilSE information pack. It is important that young people are able to shape research based on their lived experiences. Several international charities and organisations have offered support and knowledge in advising the process.

Results: At early workshop meetings, young people with invisible illnesses and their parents were able to offer personal accounts and experiences which highlighted that the most common themes were problems with communication and trust, as well as difficulty in understanding the erratic nature of many chronic illnesses. From this research, a draft information pack was written by the RAilSE committee, which was later presented to young people, parents, health and education professionals and charity representatives. All stakeholders were able to offer their expertise from their respective fields. Feedback was overwhelmingly positive and any adjustments are to be made in the coming weeks. The final pack will be completed and ready for distribution by the end of summer 2018 .

Conclusion: The project has been a successful example of young patient led research and highlights the importance of self-management in young people living with invisible chronic illnesses. The collaboration between young people, parents, and education and health professionals has highlighted the necessity for cooperation between all stakeholders for the benefit of the young person.

Disclosure of Interest: None declared

DOI: 10.1136/annrheumdis-2018-eular.7794

\section{SP0039 I GRADUATED! EDUCATION FOR CHILDREN AND ADOLESCENTS WITH RMDS}

\section{T.C. Wilhelmer. Youth Ambassador, Austrian Rheumaliga, Lauterach, Austria}

Communication is the key to success in practically every situation. Without communicating to your counterpart, how should they understand your own situation? When it comes to studying with a chronic illness we need to know how the illness affects our ability. We need to communicate what we are able to do and where we need support. When I started my Master Degree I have been honest from the very beginning. I never kept my rheumatic disease and the disability that comes with it a secret. Being open from the very beginning gives yourself and your university, school or even workspace the opportunity to adapt to your abilities. Hiding your disability will make it hard for yourself to keep up with your class. Your fellow stu dents and teachers not knowing what your limitations are will most certainly lead to misunderstandings.

Many pupils and students do not know that there are laws and regulations that could help them to get through school easier. For example you are allowed to have longer writing times in exams, or use your computer for typing texts instead of having to write by hand. This helps to prevent pain in your joints. There are 